\title{
Ship Detection in Madura Strait and Lamong Gulf using Sentinel-1 SAR Data
}

\author{
Filsa Bioresita1, 2,*, Cherie Bhekti Pribadi², and Hana Sugiastu \\ Firdaus $^{3}$ \\ 1 Laboratoire Image, Ville et Environnement, Department of Geography, University of \\ Strasbourg, Strasbourg, France \\ 2 Department of Geomatics Engineering, Institut Teknologi Sepuluh Nopember, \\ Surabaya, Indonesia \\ 3 Department of Geodesy Engineering, Diponegoro University, Semarang, Indonesia \\ *e-mail: filsa.bioresita@gmail.com
}

\begin{abstract}
During the recent years, maritime surveillance has been receiving a growing interest. Ship detection and identification are parts of maritime surveillance in order to dealing with illegal fishery, maritime traffic, sea border activity, or oil spill detection and monitoring. Nowadays, Synthetic Aperture Radar (SAR) as one of active remote sensing technology provide signals to penetrate cloud, can be advantage to be used in tropical region with the intention to monitor sea objects on the sea surface from the space. The availability of Sentinel-1 as SAR imaging mission, providing continuous all-weather, day-and-night imagery, makes it ideal for precise cueing and location of ship activities at sea. Utilization of CFAR (Constant False Alarm Rate) algorithm provided by SNAP (Sentinel Application Platform) software from ESA show rapid detection of ship in the study areas (Madura Strait and Lamong Gulf). Compared with manual ship extraction method, it gives sufficient results.
\end{abstract}

\section{Keywords}

Maritime surveillance, ship detection, SAR, Sentinel-1, CFAR

Citation: Bioresita, F., Pribadi, C.B., Firdaus, H.S.: Ship Detection in Madura Strait and Lamong Gulf using Sentinel-1 SAR Data. In: I.W. Mustika, I. Kartini. (eds.): Proceeding of the 3 rd International Conference on Science and Technology, Vol. 1, pp. 13-23. UGM Digital Press Physical Science and Engineering, Yogyakarta (2018).

Published: October, 2018

\section{Introduction}

During the recent years, maritime surveillance has been receiving a growing interest. Especially in Indonesia which seventy percent of its territory is sea, maritime monitoring become really important. Maritime surveillance is essential for creating maritime awareness, knowing what is happening at sea. One activity included in maritime surveillance is ship identification which very useful for dealing with illegal fishery, maritime traffic, sea border activity, or oil spill detection and monitoring [1]. Ship position detection involve personal data, for example, can concern to fishing vessel identification number, a license number, external registration number, or other unique identifiers which can lead directly or indirectly to person identification. It will be useful for gathering information of fishing assets [2]. Ship detection system is marine monitoring system used to keep track of vessel movements and provide navigational safety in a limited geographical area [3].

Madura Strait and Lamong Gulf are two areas in East Java which have high sea activity. In Madura Strait, there is Tanjung Perak port as a famous national port gateway, which act as shipping traffic link 
between west parts of Indonesia with east part of Indonesia. As anticipation of overcapacity in Tanjung Perak port, Lamong Bay port was built in Lamong Gulf area. Increasing activity that occur in these ports can increase ship volume around Madura Strait and Lamong Gulf. Increase of ship volume can become a threat to sea security. Thus, enhancement of maritime monitoring must be done in this area, especially in ship detection system.

Nowadays, the use of remote sensing technology is become advantageous to support monitoring and surveillance of sea and coastal areas and to prevent security threats to ports facilities. Synthetic Aperture Radar (SAR) as one of active remote sensing technology, provide signals to penetrate cloud, which can be advantage to be used in tropical region with the intention to monitor sea objects on the sea surface from the space [1]. It also can detect breaking waves region and surf zone in coastal areas [4]. With the availability of Sentinel-1 as imaging SAR mission providing continuous all-weather, day-and-night imagery at C-band, monitoring ship on sea surface will be easier.

Sentinel-1, from European Space Agency (ESA), uses wide area coverage with improved revisit times and is able to potentially detect small ships. The mission's ability to observe in all weather and in day or night time, makes it ideal for precise cueing and location of ship activities at sea, allowing for more efficient and cost-effective use of other security assets, such as patrol aircraft and ships [5]. SNAP (Sentinel Application Platform) software from ESA provide a tool using Utilization of CFAR (Constant False Alarm Rate) algorithm to detect sea object. The tool is called ocean object detection and allow rapid ship detection mapping. Thus in this study, the aims are detected ship position using that tool and compare it with manual method for object extraction.

\section{Data and Study Areas}

Sentinel- 1 IW GRDH is an image data that used for ship detection in this study. Sentinel data is provided by European Space Agency (ESA) and can be accessed and downloaded free of charge from their website. In this study, Level-1 product with Interferometric Wide Swath (IW) mode and Ground Range Detected (GRD) with high resolution $(20 \times 22 \mathrm{~m})$ type was used to identify location of ship activities in Madura Strait and Lamong Gulf. Level-1 Ground Range Detected (GRD) products was used because in this study, only backscattering information was needed. In that type of product, phase information is lost and consist of focused Synthetic Aperture Radar (SAR) data that has been detected, multi-looked and projected to ground range using an Earth ellipsoid model. Acquisition mode uses Interferometric Wide Swath (250 km swath), with dual polarization (VV+VH) and descending pass [6].

Sentinel-1 uses C-band SAR that nominal frequency range, from 8 to $4 \mathrm{GHz}$ (3.75 to $7.5 \mathrm{~cm}$ wavelength) within the microwave (radar) portion of the electromagnetic spectrum. C-band are generally not hindered by atmospheric effects and are capable pass through tropical clouds and rain showers so that monitoring ship on sea surface will be easier [6]. Fig. 1 shows backscattering image of Sentinel-1 imagery (26 September 2016) that is used in this study.

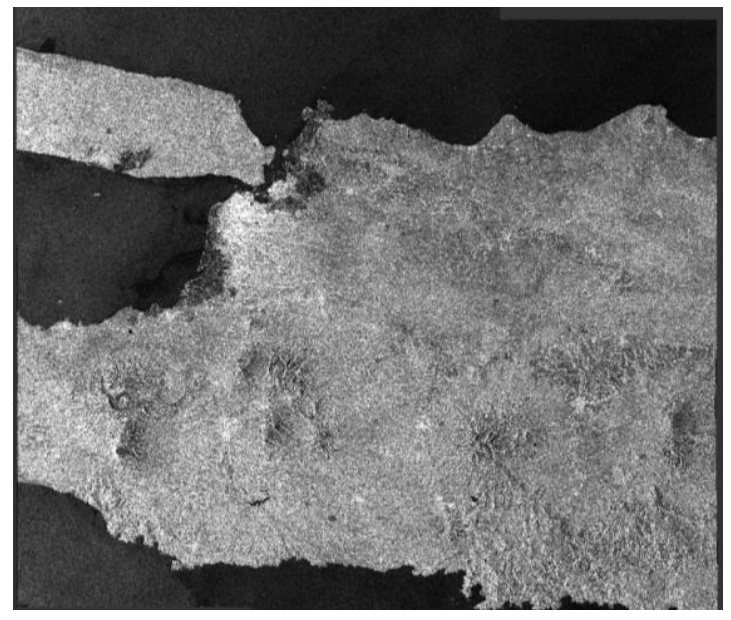

Fig. 1 Sentinel-1 IW GRDH (26 September 2016) 


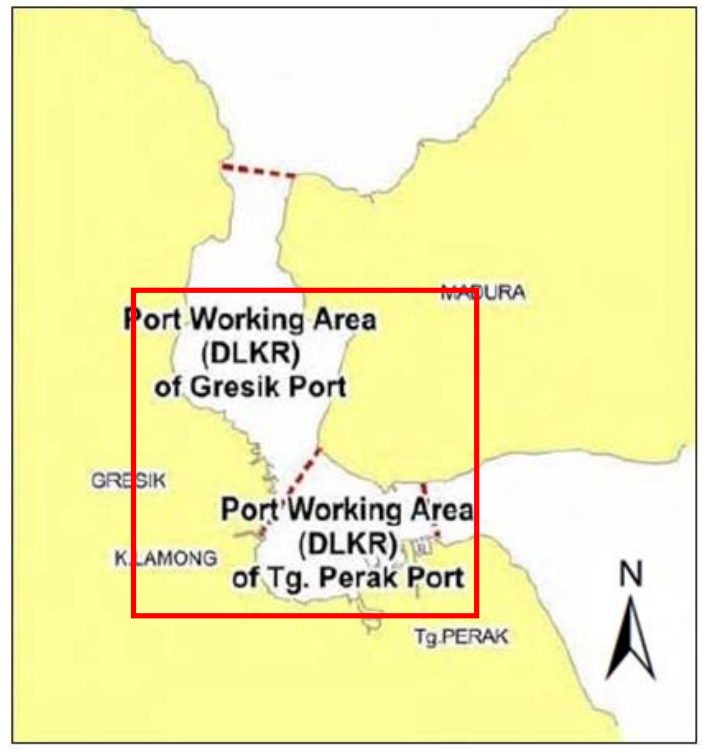

Fig. 2 Study areas (Madura Strait and Lamong Gulf)

Madura Strait and Lamong Gulf are the busy shipping lane in both national and international scale which is study areas in this research that shown in Fig. 2. They consist of several ports and one of them is Tanjung Perak port. Tanjung Perak port being the main port in Eastern Indonesia and national port gateway to Surabaya. This port has many kinds of facilities such as docks, naval base, Suramadu Bridge, and some industries. Increasing activity of shipping also needed facility improvement to sufficient the demand that increased and changed along coastline between Tanjung Perak and Gresik [7]. The development of Lamong Bay port is a solution to improve traffic container.

Lamong Bay port being strong magnetic for international shipping to process loading and discharging ships and ships lean. The increase activity that occur in these ports can increase ship volume as transportation along Madura Strait and Lamong Gulf, thus ship detection in those areas is very important. In this study areas, Surabaya port areas devoted to navigation and boat safety. This area consists of port working area (DLKR) and port interest's area (DLKP), while technically DLKP included in DLKR. Port working area (DLKR) of Tanjung Perak port have land areas wider (517 Ha) than Port working area (DLKR) of Gresik port ( $96 \mathrm{Ha}$ ). Port working area (DLKR) of Tanjung Perak port have territorial waters of the port less (4675 Ha) than Port working area (DLKR) of Gresik port (8149 Ha) [7].

\section{Methods}

The general idea for this study is detected ship in the Lamong bay and Madura strait using one of active remote sensing data i.e. Sentinel-1. We used two different chain processing method and compared those two methods. In [8-10] and the others proposed CFAR algorithm for ship detection in SAR imagery. That algorithm then applied in SNAP tools for ocean object detection. Through this study, we will explore Sentinel-1 data for rapid ship detection in the study areas using that SNAP tools. In the same time, we also try to extract ship object using manual threshold extraction. Fig. 3 below show overall methods in SNAP tools and manual steps processing. 


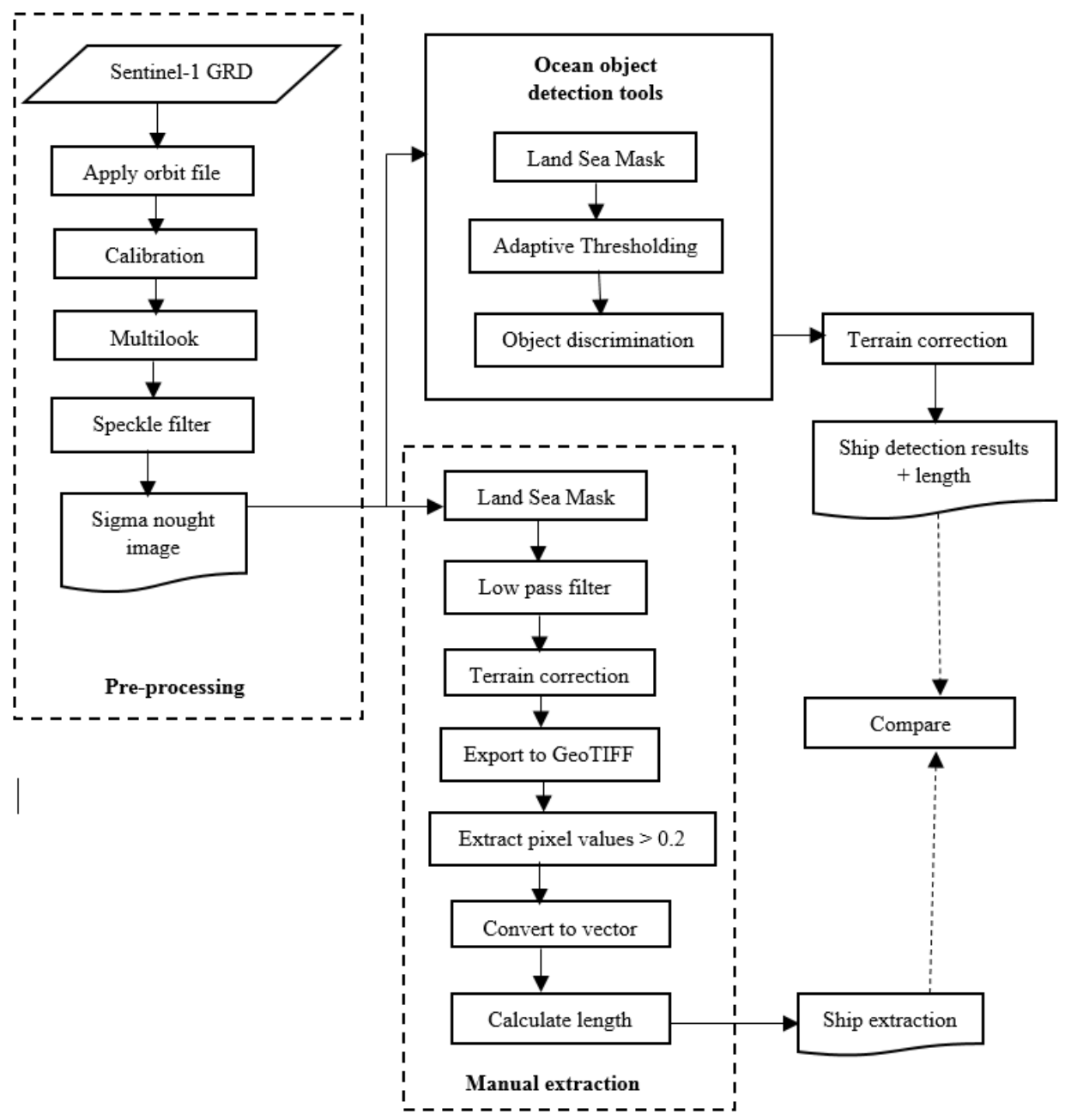

Fig. 3 Flowchart showing the overall methods used in this study

\subsection{Pre-processing}

Images pre-processing must be done for Sentinel-1 IW GRDH in order to reduce SAR effect like orbit errors or speckle noise. Sentinel-1 images data actually have some problems with their orbit information in metadata. This problem caused a non-accurate effect when they are superimposed. In order to overcome this problem, orbit data of Sentinel-1 images must be updated with available orbit file data. Thus a process called apply orbit file was done.

Raw data of Sentinel-1 IW GRDH is amplitude image. It is important to change amplitude image to calibrated product for quantitative use or SAR images. Sigma-nought image as calibrated product then was selected. In order to reduce speckle noise, multilooking and speckle filtering were applied. Lee filter with window $3 \times 3$ was used as spatial filtering method in this study. After this pre-processing step, sigma-nought image from Sentinel-1 data will be ready for ship detection process.

\subsection{Ocean Object Detection}

Ocean object detection operator detects object such as ships on sea surface from SAR imagery. The following are major processing steps from this operation:

1. Land-sea masking

A land-sea mask is generated to mask land area. Thus, detection can be only focused in sea surface. This operation can be done using Digital Elevation Model (DEM) which in this study we used SRTM (Shuttle Radar Topography Mission) data which is downloaded automatically while processing in SNAP. In this process, extended pixel masking from shoreline can be done to avoid detected another object in some port areas. 


\section{Pre-screening}

Constant False Alarm Rate (CFAR) detector is used as the first step in screening process. The idea is to find extraordinarily bright pixels compared to the other pixels in surrounding area. The detection criterion can be expressed as

$x_{t}>T \Leftrightarrow T A R G E T$

when $x_{t}$ is the pixel under test and $T$ is a given threshold. Then PFA (Probability of False Alarm) was given by the formula below. $f(x)$ is ocean clutter probability density function and $x$ is range through the possible pixel values

$P F A=\int_{T}^{\infty} f(x) \mathrm{dx}$

and the above detection criterion is equivalent to the criterion below

$\int_{X t}^{\infty} f(x) \mathrm{dx}<P F A \Leftrightarrow$ TARGET

The above detection criterion can be further expressed as formule below, if Gaussian distribution is assumed for the ocean clutter.

$x_{t}>\mu_{b}+\sigma_{b} t \Leftrightarrow$ TARGET

where $\mu_{b}$ is the background mean, $\sigma_{b}$ is the background standard deviation and $t$ is a detector design parameter which is computed from $P F A$ by the following equation

$P F A=\frac{1}{2}-\frac{1}{2} \operatorname{erf}\left(\frac{t}{\sqrt{2}}\right)$

The valid PFA value is in range $[0,1]$.

In real implementation of the two-parameter CFAR detector, object detection is performed in an adaptive manner by the Adaptive Thresholding operator. For each pixel under test, there are three windows, namely target window, guard window and background window, surrounding it (see Fig. 4). Normally the target window size should be about the size of the smallest object to detect, the guard window size should be about the size of the largest object, and the background window size should be large enough to estimate accurately the local statistics.

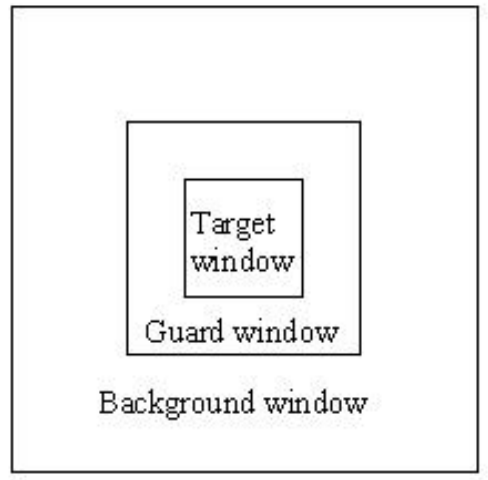

Fig. 4 Window setup for adaptive thresholding algorithm

The operator consists of some steps below:

- Compute detector design parameter $t$ from user selected $P F A$ using equation before.

- Then computes background mean $\mu_{b}$ and standard deviation $\sigma_{b}$ using pixels in the background ring.

- Next computes the mean value $\mu_{t}$ of the target window.

- If $\mu_{t}>\mu_{b}+\sigma_{b}{ }^{*} t$, then the center pixel is detected as part of an object, otherwise not an object.

- Move all windows by one pixel to detect the next pixel. 


\section{Discrimination}

The discrimination operation is conducted by the Object Discrimination operator. During this operation, false detections are eliminated based on simple target measurements.

- The operator first clusters contiguous detected pixels into a single cluster.

- Then the width and length information of the clusters are extracted.

- Finally based on these measurements and user input discrimination criteria, clusters that are too big or too small are eliminated.

In this study, $50 \mathrm{~m}$ and $250 \mathrm{~m}$ were determined for minimum and maximum target size. Those values were selected based on ship size estimation and some preliminary tests. Terrain correction process was the last step applied to make representations geometry of the image will be close to the truth and to minimize the influence of the local incident angle to the image.

\subsection{Manual Extraction}

The principal concept of ocean object detection tool and manual threshold extraction process is same. Using filtering and extract bright pixel using threshold. Yet, in the manual threshold extraction processing, each step will be performed separately and one by one. First, same with ocean object detection tool, sea mask was performed, then in order to reduce some noise and make interested object look more clearly, low pass filter with $3 \times 3$ window was done. After that, terrain correction was conducted for geometric correction and image data was exported to GeoTIFF format to facilitate the next process. The next step was using threshold value (0.2) to extract ship object. The threshold value was determined after several preliminary tests. With the aim of getting vector format of detected ship, image result is then converted to vector, and their length attributes were calculated.

\section{Results and Discussions}

\subsection{Land Mask}

Land Mask operation in SNAP will turn any pixels on land into no data value. The operator will automatically download a course SRTM 5 min DEM the first time it is used. This DEM is used to very quickly determine if a pixel is on land or in the ocean. Fig. 5 show comparison between land mask result with shoreline extension and without shoreline extension. From that figure, using shoreline extension can delete some artificial surfaces in the coastline areas. It will be useful to minimize error detection between ship and port facilities. However, the determination of extended mask pixel must be done carefully and using visual observation test.
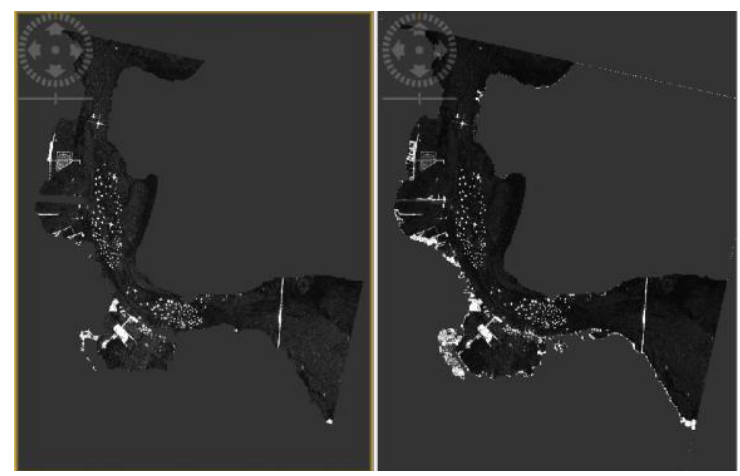

Fig. 5 Comparison between land mask result; a with shoreline extension (30 pixels), b without shoreline extension 


\subsection{Rapid Ship Detection Result}

In the ship detection process using ocean object detection tool in SNAP, ship was extracted from two sigmanought images, VV and VH. The results show difference, some object are not detected in sigma-nought VV, only detected in sigma-nought $\mathrm{VH}$ and vice versa. However, many objects are detected from both of them, sometimes with slightly different position. Fig. 6 show comparison between those two results.

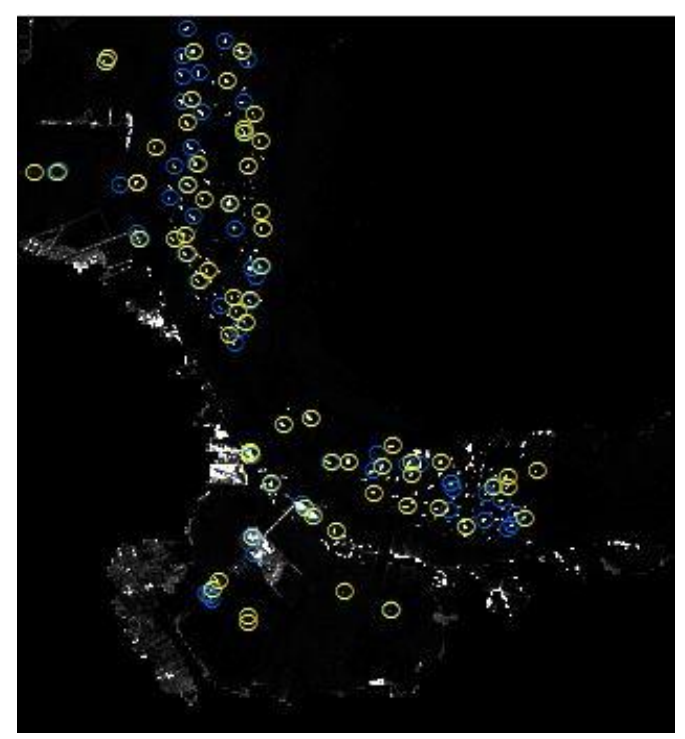

Fig. 6 Ship detection results from sigma-nought VH (blue) and sigma-nought VV (yellow)

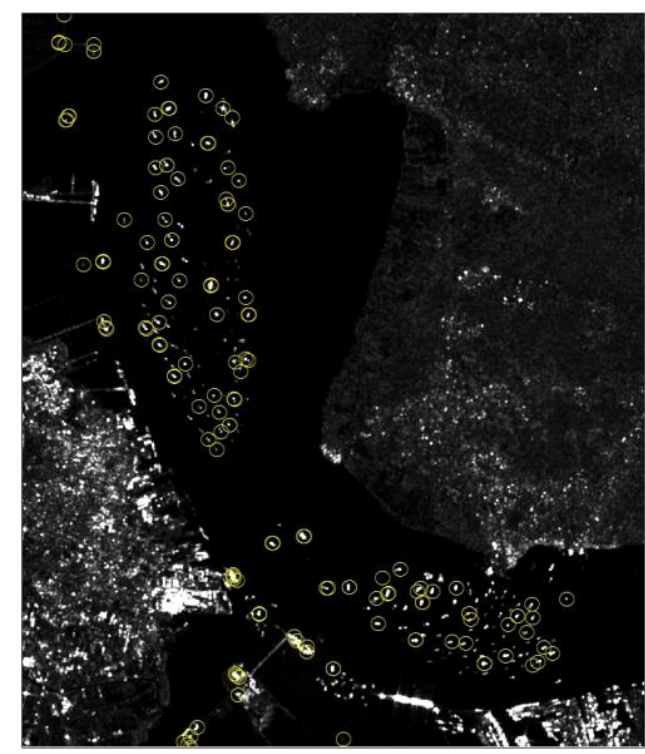

Fig. 7 The distribution of ship detection using ocean object detection tools

Fig. 7 tells about ship detection which has scattered at Lamong Bay and Madura Strait. In that figure, ship detection was combination from sigma-nought VV and VH results. By using this method, some ports or artificial surfaces along shorelines areas are detected as ships but it can be removed manually using visual observation. Fig. 8 show about thirty four percent (34\%) of ship detection from this method is estimated as false alarm after visual observation. Even though, using this method, some ships cannot be extracted, but, it already can be initiation for ship detection. From this method, length of ship can be automatically calculated. The longest detected ship is about $150 \mathrm{~m}$ and the smallest ship is about $30 \mathrm{~m}$. 


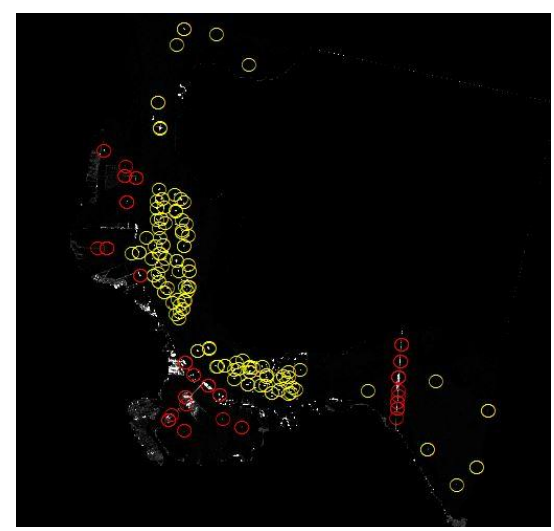

Fig. 8 Estimation of false alarm (red) and correctly identified (yellow) concerning ship detection using ocean object detection tools

\subsection{Manual Ship Detection Result}

In this manual method, only sigma-nought VV images would be used. Fig. 9 indicated about ship extraction at Lamong Bay and Madura Strait using manual method. By using this method, all of ships detected, but it is difficult to determine a threshold for ships extraction. Same with rapid method before, some artificial surface along coastline areas are detected as ships but it can be removed manually using visual inspection. Fig. 10 show estimation of false alarm from ship extraction using manual extraction method. Those false alarm distribution is about forty five percent (45\%) from all objects extraction result. The longest detected ship from this method is about $390 \mathrm{~m}$ and the smallest ship is about $14 \mathrm{~m}$.

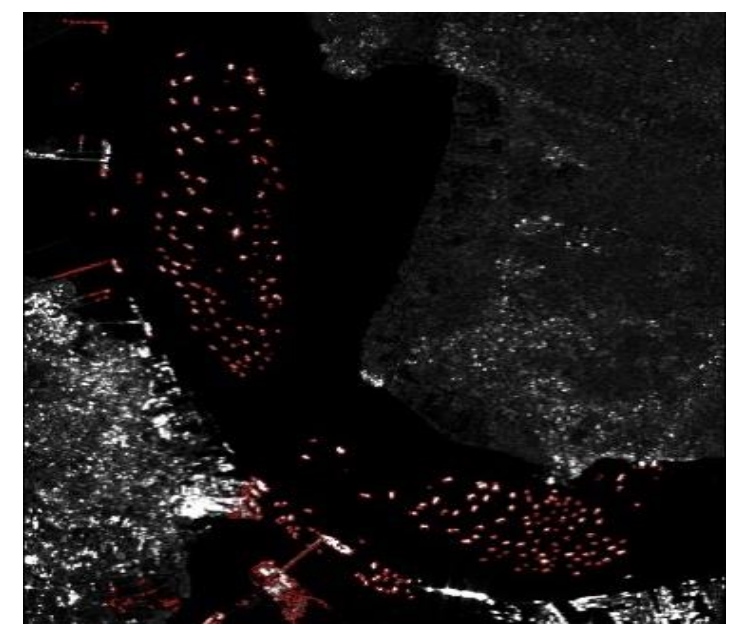

Fig. 9 The distribution of ship detection using manual extraction methods 


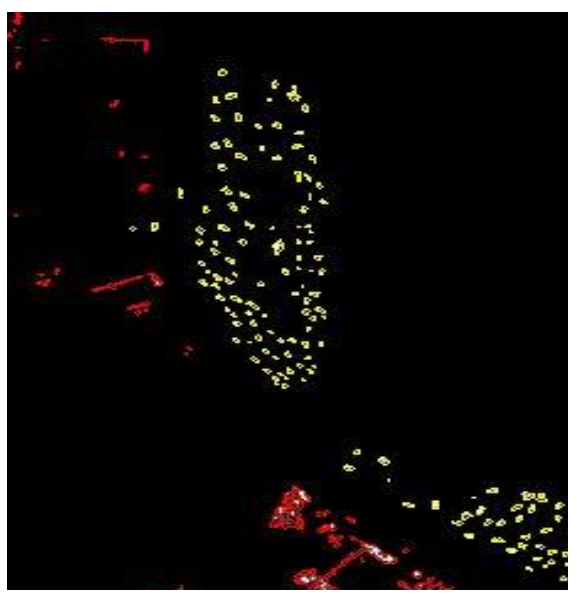

Fig. 10 Estimation of false alarm (red) and correctly identified (yellow) concerning ship detection using manual extraction methods

Based on false alarm percentage from rapid detection and manual extraction, rapid detection has plus value. It processes with minimal time consuming and less false alarm result. However, it cannot be detected all ship in the study areas. On the contrary, manual extraction can extract all ships which exists in the study areas, it can extract smaller and bigger ships. Yet, it produces higher false alarm estimation and take more time to process.

Fig. 11 show about final ship detection map from those two methods on Sentinel-1 IW GRD image. The distribution of ship detection using ocean object detection tools less than the distribution of ship detection using manual extraction methods. Geographically, the pattern of ship detection distribution using both methods are same. However, ships appear more clearly visible and more complete using the manual extraction method.

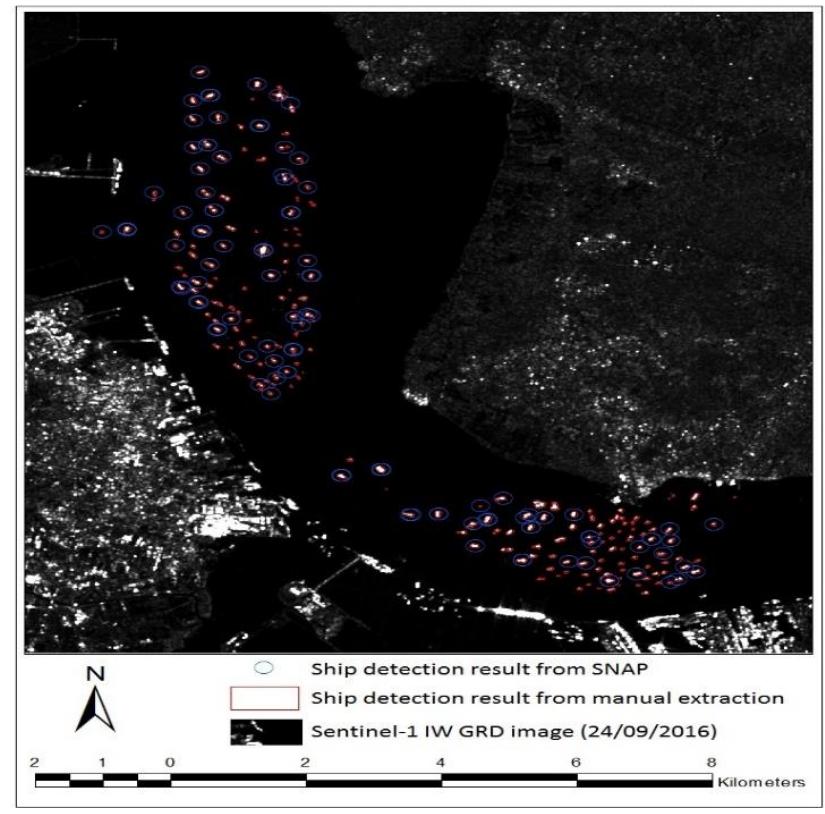

Fig. 11 The distribution of ship detection using ocean object detection tools and manual extraction methods

Sentinel-1 has many useful advantages because it covers wide areas, cloud free, and has short revisit time. However, its original resolution is about $20 \mathrm{~m}$. After resampling, it can become $10 \mathrm{~m}$ but the information inside the pixel cannot be changed into more detail. Thus, it cannot detect very detail object. In the ship extraction, for rapid method the smallest ship which can be detected has a length of $30 \mathrm{~m}$. It means, about one and half pixels. In the manual extraction, the smallest ship has a length of $14 \mathrm{~m}$ but also with higher false alarm result. Yet, the result of rapid detection mapping in SNAP using Sentinel-1 has 
already representing the presence of ships in the study area. Therefore, it can be used in wider areas for ship detection.

\section{Conclusions}

Ship detection is part of maritime surveillance that examined in this study using Sentinel 1 IW GRD SAR data. Madura Strait and Lamong Gulf are areas which have high sea activity and several ports. Increasing activity that occur in these ports can increase ship volume around Madura Strait and Lamong Gulf. Sentinel1 uses C-band SAR are generally not hindered by atmospheric effects and are capable pass through tropical clouds and rain showers, thus identification ship on sea surface will be easier. In this study, ship detection using Constant False Alarm Rate (CFAR) algorithm provided by Sentinel Application Platform (SNAP) for ocean object detection which is rapid ship detection method was tested.

The results from rapid method process was compared with manual ship extraction method. The results indicate that some ports or artificial objects along shorelines areas are detected as ships, indicated with 34 $\%$ false alarm estimation after visual observation. Compared with manual ship extraction, some artificial objects along coastline areas also detected as ships, $45 \%$ false alarm. Based on percentage of false alarm, rapid ship detection produces less false alarm result with minimal consuming time process than manual ship extraction but cannot detected all ship in the study areas. Manual ship extraction can extract all ships in the study areas but produce higher false alarm estimation and take more time to process. Rapid and manual extraction method can calculate length of ship, but rapid extraction has plus value because can be automatically calculate length of ship. Generally, both methods can be used to ship detection and give sufficient results. However, in the case of Sentinel-1, ocean object detection in SNAP tools is suitable to use for rapid mapping.

Acknowledgments This research is supported by the Indonesia Endowment Fund for Education (LPDP), Ministry of Finance, Republic of Indonesia. The authors would like to thank the European Space Agency for the provision of Sentinel-1 data.

\section{References}

1. Attema, E.: Mission requirements document for the european radar observatory sentinel-1. ES-RSESA-SY-0007. $1^{\text {st }}$ Ed., $4^{\text {th }}$ Rev. Requirement Specification. (2005).

2. Susiloningtyas, D., Boer, M., Adrianto, L., Julianto, F.: The influence of fishing assets and migration time to catch squid fisheries on seasons variability. Indonesian Journal of Geography 46(1) (2014).

3. IALA Vessel Traffic Service Manual. Edition 5. 2012. International Association of Marine Aids to Navigation and Lighthouse Authority.

4. Retnowati, A., Marfai, M.A., Sumantyo, J.T.S.: RIP Currents Signatures Zone Detection on ALOS PALSAR Image at Parangtritis Beach, Indonesia. Indonesian Journal of Geography 44(1),12-27, June (2012).

5. ESA, Maritime monitoring. ESA Sentinel Online. https://sentinel.esa.int/web/sentinel/userguides/sentinel-1sar/applications/maritime -monitoring. Accessed in 8 May 2017.

6. ESA, Sentinel-1 SAR. ESA Sentinel Online. https://sentinel.esa.int/web/sentinel/userguides/sentinel-1-sar. Accessed in 7 May 2017.

7. ALMEC Corporation and Japan port consultants: The study for development of the greater Surabaya metropolitan ports in the Republic of Indonesia. http://open_jica report.jica.go.jp/pdf/11868676.pdf. Accessed in 5 May 2017.

8. Crisp, D. J.: The State-of-the-Art in ship detection in synthetic aperture radar imagery. DSTO-RR0272, (2004). 
9. Hwang, S., Ouchi, K.: On a Novel Approach Using MLCC and CFAR for the Improvement of Ship Detection by Synthetic Aperture Radar. IEEE Geoscience and Remote Sensing Letters 7(2), (2010). doi: 10.1109/LGRS.2009.2037341

10. Ai, J., Qi, X., Yu, W., Deng, Y., Liu, F., Shi, L.: A New CFAR Ship Detection Algorithm Based on 2-D Joint Log-Normal Distribution in SAR Images. IEEE Geoscience and Remote Sensing Letters.7(4), (2010). doi: 10.1109/LGRS.2010.2048697 